\title{
Independent segregation of von Hippel-Lindau disease and cerebral cavernomas
}

\author{
Andrew R Webster, Richard B Fisher, Lionel Ginsberg, Eamonn R Maher
}

Department of

Pathology, University of Cambridge,

Cambridge, UK

A R Webster

R B Fisher

E R Maher

\section{Department of}

Ophthalmology,

Addenbrooke's

Hospital, Cambridge,

UK

A R Webster

Department of Clinical Neurosciences, Royal Free Hospital School of Medicine, London, UK

L Ginsberg

Correspondence to: Professor Eamonn R Maher, Division of Medical Genetics, Department of Paediatrics and Child Health, University of Birmingham, Birmingham Women's Hospital,

Edgbaston, Birmingham B15 2TF, UK.

Received 15 July 1996 and in revised form 14 March 1997 Accepted 19 March 1997

\begin{abstract}
A probable diagnosis of von HippelLindau disease was made in a two generation family in which the proband had a phaeochromocytoma, renal cysts, and multiple cerebral cavernomas. His sister had multiple similar cerebral vascular lesions and his father died from renal carcinoma aged 42. Although the family did not satisfy the conventional diagnostic criteria for von Hippel-Lindau disease, an underlying germline mutation in the von Hippel-Lindau disease tumour suppressor gene was identified in the proband. Molecular genetic analysis not only confirmed the putative diagnosis of the disease in the proband but also showed that the cerebral vascular lesions segregated independently from the von HippelLindau disease mutation. This report exemplifies how molecular genetic investigations can enhance the diagnosis and management of families with suspected von Hippel-Lindau disease, particularly when the manifestations, as in this family, are not typical.
\end{abstract}

(F Neurol Neurosurg Psychiatry 1997;63:665-668)

Keywords: von Hippel Lindau disease; cavernoma; mutation

Von Hippel-Lindau (VHL) disease is a dominantly inherited familial cancer syndrome with an estimated birth incidence of heterozygotes of about 1 in $36000 .^{12}$ The main manifestations include benign vascular tumours (haemangioblastomata) of the retina, cerebellum, and spinal cord, renal carcinoma, phaeochromocytoma, and renal and pancreatic cysts. Retinal and CNS tumours are the most frequent manifestations occurring in $70 \%$ and $84 \%$ of gene carriers respectively by the age of $60 .^{2}$ Supretentorial tumours are rare in VHL disease but have been reported. ${ }^{34}$ The diagnosis of the disease is dependent on finding (1) two haemangioblastomas, (2) a haemangioblastoma and a visceral complication, or (3) one manifestation if there is a family history of haemangioblastoma. To identify gene carriers within VHL pedigrees and to detect retinal, adrenal, and renal tumours at a presymptomatic stage when treatment is most effective, a screening protocol has been recommended. ${ }^{3}$ Although the disease penetrance is close to $100 \%$ by the age of 60 years, the variability in expression can often complicate accurate clinical diagnosis.

The disease was found to be linked to markers on chromosome $3 \mathrm{p}^{5}$ and the gene was later characterised by a positional cloning approach. ${ }^{6}$ Mutations have been identified in most VHL kindred ${ }^{7}$ and include deletions of the whole gene, deletion of one or two of the three exons, or intragenic point mutations including missense, nonsense, microdeletions, or insertions. A phenotype-genotype relation is evident in that missense mutations are associated with a high risk of phaeochromocytoma and mutations predicted to cause an absent or truncated protein produce a low risk of this complication. Recent advances in the understanding of the molecular genetics of VHL disease allow presymptomatic diagnosis of at risk relatives by linkage analysis using informative markers close to the VHL gene ${ }^{9}$ or by mutational analysis when the family mutation has been determined.

In addition to the classic features of the disease, many rare complications have been reported. In some cases it is not clear whether these are chance associations or true rare manifestations. We report a family in which a clinical diagnosis of probable VHL disease was made and in which multiple cerebral cavernomas occurring in two siblings seemed to be a rare manifestation. Molecular genetic analysis confirmed a diagnosis of VHL disease in one family member but also showed that the cerebral vascular lesions were not manifestations of the disease.

\section{Patients and methods}

CLINICAL DETAILS

Figure 1 shows the family pedigree.

Patient III:2 presented at the age of 22 with blurred vision and headaches. Examination disclosed hypertension and grade IV hypertensive retinopathy and subsequent investigation showed left adrenal and periaortic phaeochromocytomas. These were successfully resected with relief of hypertension and sympathetic symptoms. At the age of 31 he had two epileptic 


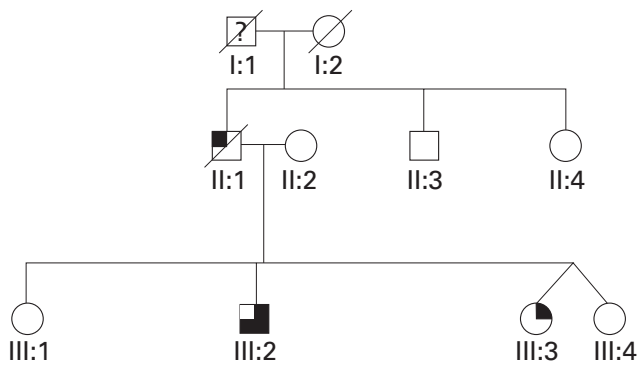

\begin{tabular}{|c|c|}
\hline & Symbol definitions \\
$\square$ & Unaffected \\
\hline$?$ & Possibly affected \\
\hline & cerebral vascular lesions \\
$\square$ & renal cell carcinoma \\
$\square$ & renal cysts, cerebral lesions, phaeo
\end{tabular}

Figure 1 Family pedigree. The diagonal slash across a symbol indicates that the person is deceased.

seizures. Brain MRI showed multiple cerebral cavernomas (fig 2A). A diagnosis of VHL disease was made on the basis of these findings. Further screening disclosed multiple renal cysts but no evidence of retinal angiomata or recurrence of phaeochromocytoma. He has no children. Blood DNA was analysed for VHL markers and mutation screening.

Patient III:3 developed epilepsy at the age of 25 which has subsequently been successfully controlled on medication. Brain MRI showed cerebral vascular lesions similar to those of her brother (III:2) (fig 2B). There were no abnormalities in the cerebellum, brainstem, or spinal cord. Retinal examination showed no evidence of angiomata. Abdominal imaging was normal. She had borderline hypertension that did not require treatment and urinary VMAs were within normal limits. She has no children.
Blood DNA was analysed for VHL markers and mutation screening.

Other family members

Member II: 1 , the father of III:2 and III:3, died aged 42 from renal carcinoma. He had no other manifestations of VHL disease that were known to his relatives; II:2, the mother of III:2 and III:3, is aged 55 and fit and well with no manifestations of the disease. Member III: 4 is the dizygotic twin of III:3. She is mentally handicapped and has no evident manifestations of VHL disease. Member III: 1 is the eldest sister of III:2 and III:3 and is aged 37. These remaining members of the family were either unavailable for interview or declined to donate a blood sample for DNA analysis.

\section{Molecular genetic analysis}

Blood was available from patients III:2 and III:3 and DNA was extracted using standard methods. The patients were typed for the highly informative microsatellite polymorphism D3S1038 as described previously ${ }^{9}$ and were found to share one allele. To detect the specific VHL mutation, Southern blot analysis was first performed on blood DNA from III:2 to detect or exclude a large deletion in the VHL gene. Five micrograms of genomic DNA was digested with $1 \mathrm{U}$ of EcoRI (Boehringer Mannheim) at $37^{\circ} \mathrm{C}$ as recommended by the manufacturers and then run overnight on a $0.8 \%$ agarose gel. The DNA was transferred to a Hybond nitrocellulose filter using standard methods and probed with VHL cDNA (g7) as described previously. ${ }^{10}$ A single band of $22 \mathrm{~kb}$ was detected after autoradiography from patient III:2 with no other bands evident suggesting the absence of a large VHL gene deletion.

The polymerase chain reaction (PCR) was used to amplify the VHL coding region in four fragments and single strand conformation polymorphism analysis was performed to
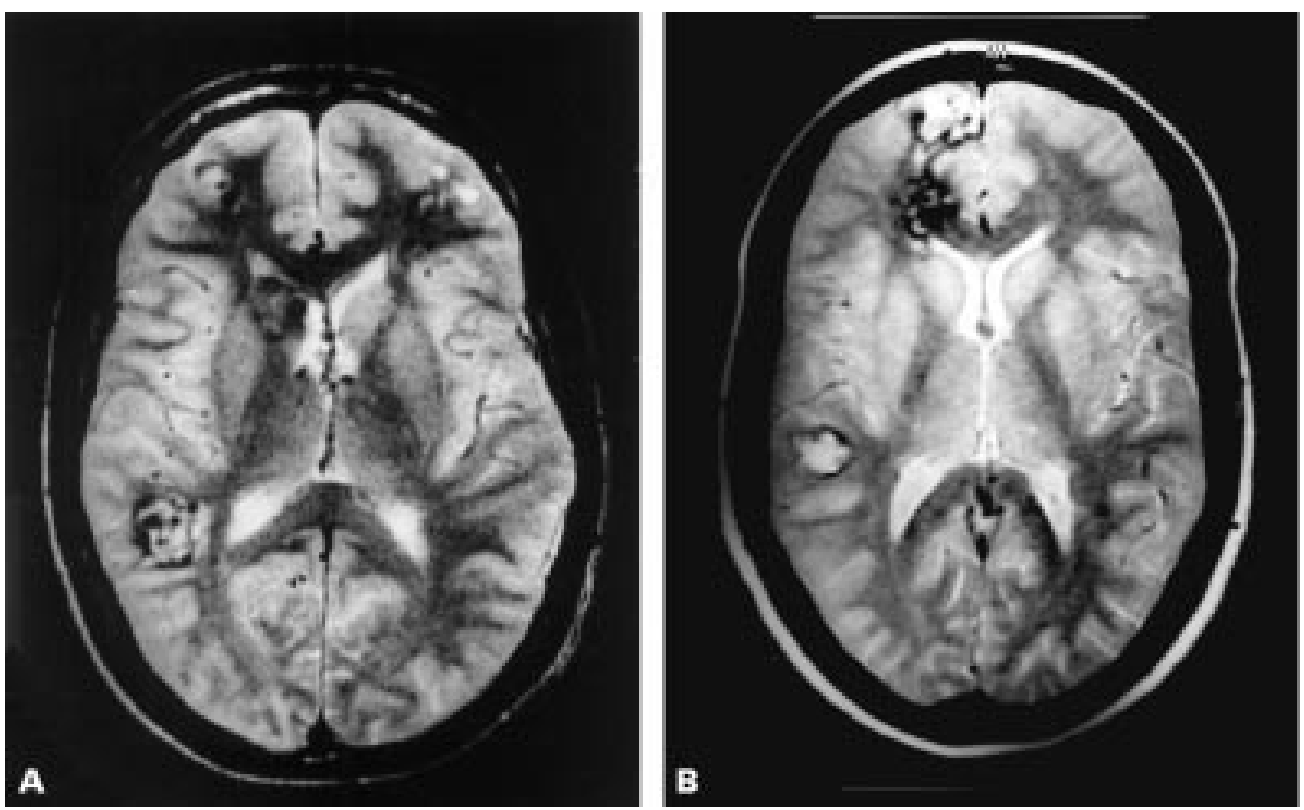

Figure 2 T2 weighted axial MRI brain sections of (A) III2 and (B) III3 showing multiple cerebral cavernomas in both siblings. 


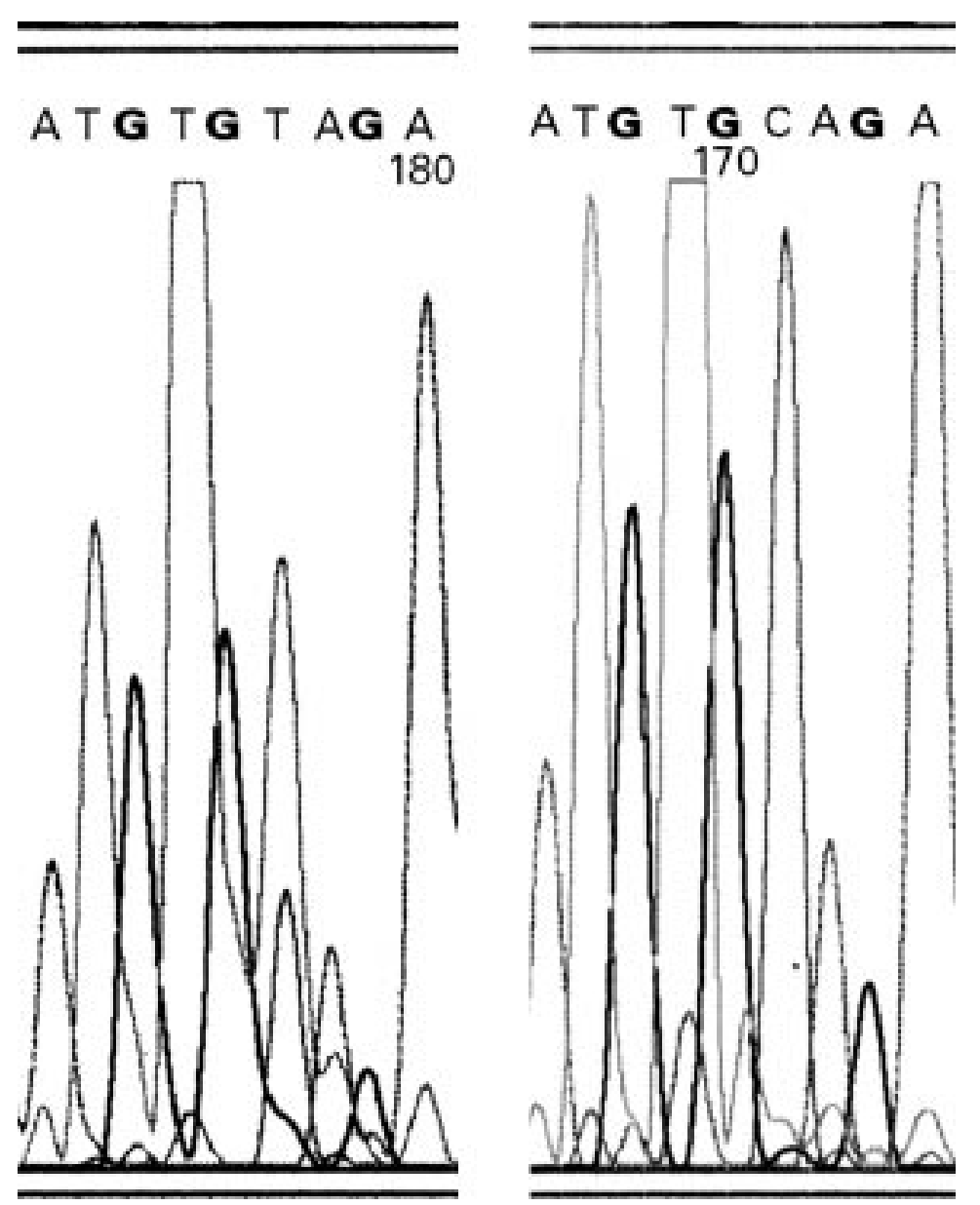

Figure 3 DNA sequence from ABI 373 automated sequencer showing the sense strand of VHL exon 3. (Left) Patient III:2 showing heterozygosity for the sequence TGTGT/CAG. (Right) Patient III:3 showing homozygosity for the normal sequence TGTGCAG.

detect intragenic mutations as described previously. ${ }^{7}$ Analysis of exon 3 showed a bandshift not seen in DNA from normal subjects. The exon 3 PCR fragment was purified using a Promega Wizard ${ }^{\mathrm{TM}}$ purification column and the fragment sequenced on the $\mathrm{ABI}^{\mathrm{TM}} 373$ automated sequencer using dye terminator chemistry (amplitaq FS) as recommended by the manufacturers.

Sequencing disclosed a $\mathrm{C}$ to $\mathrm{T}$ transition at nucleotide 796 in DNA from patient III:2 causing a nonsense mutation (glutamine to stop) at codon 195 (fig 3 left). This would be predicted to cause a truncated protein product deleted for the 19 carboxy terminal amino acids of the 213 amino acid VHL protein. Similar analysis of blood DNA from patient III:3, who was assumed to be affected by VHL disease, showed a normal SSCP pattern for exon 3 and a normal exon 3 sequence (fig 3 right).

\section{Discussion}

Symptoms and signs of CNS haemangioblastomata are common presentations of VHL disease and awareness of this rare familial disease is important to neurologists and neurosurgeons. Symptomatic cerebellar haemangioblastomata occur in about $59 \%$ of patients with the disease ${ }^{3}$ and cause neurological deficit through local pressure effects and cyst formation from exuded fluid. They can also haemor- rhage. Spinal and brainstem lesions are less common than cerebellar lesions but cause neurological symptoms in about $13 \%$ of patients. $^{3}$ The actual prevalence of CNS haemangioblastomata is much higher if asymptomatic lesions are included after MRI screening. ${ }^{11}$ Supratentorial lesions are rare in VHL disease but have been reported ${ }^{3}{ }^{4}$ and the reason for this specific distribution of CNS tumours in the disease is unknown. Haemangiomata appear as homogeneous enhancing nodules often associated with a cyst on neuroradiological imaging.

Cavernomas of the CNS are also rare with an estimated prevalence of $0.5 \% .{ }^{12}$ They present with seizures, headaches, and focal neurological deficit or they can remain asymptomatic. On MRI, there are often multiple lesions that show a heterogeneous appearance. Typically, on T2 weighted images both low intensity areas (due to haemosiderin) and high intensity areas (due to other haemoglobin breakdown products) are seen, as was the case with our patients (fig 2). Cavernomas are thought to be familial in at least $50 \%$ of cases (more when multiple lesions are present) when they show autosomal dominant inheritance. Recently a locus has been mapped to chromosome $7 \mathrm{q}$ in one large family. ${ }^{13}$

The diagnosis of gene carriers in VHL pedigrees is important as it allows accurate genetic counselling and appropriate screening for presymptomatic detection of treatable manifestations. The variability of VHL disease can obfuscate the diagnosis. The utility of molecular genetic testing in the clarification of diagnosis in such situations is exemplified by this report, which illustrates the danger of overinclusiveness. Without such tests, the genetic counselling offered to this family, particularly patient III:3, would have been inappropriate. Other manifestations that can lead to diagnostic confusion include renal cysts, unusual retinal lesions not typical of angiomata, and other rare lesions such as liver cysts and liver haemangiomata. ${ }^{4} 14$

Susceptibility to phaeochromocytoma is low in families with mutations in which the VHL protein is deleted or truncated..$^{15}$ The explanation for this phenotype-genotype relation, which was not confirmed in our patient (III:2) is uncertain but may indicate tissue specific functions of the VHL protein. One other phaeochromocytoma positive VHL family has been shown to have a nonsense mutation at the same codon as the family reported here. ${ }^{7}$ This suggests that the carboxy terminal 19 amino acids are necessary for normal tumour suppressor function.

We thank the Guide Dogs for the Blind Association, the Cancer Research Campaign (CRC), Action Research, and the National Kidney Research Fund for their financial support of the von Hippel-Lindau disease genetics research. We are grateful to Dr $\mathrm{J}$ Gibbs for assistance with clinical data and Professor SR Bloom for help with the diagnostic process.

1 Maher ER, Iselius L, Yates JR, Littler M, Benjamin C, Harris R, et al. Von Hippel-Lindau disease: a genetic study. $\mathcal{F}$ Med Genet 1991;28:443-7.

2 Maher ER, Webster AR, Moore AT. The clinical features and molecular genetic aspects of von Hippel Lindau disease. Ophthalmic Genet 1995;16:79-84. 
3 Maher ER, Yates JRW, Harries R, Benjamin C, Harris R, Ferguson-Smith MA. Clinical features and natural history

of von Hippel-Lindau disease. Q f Med 1990;77:1151-63. Sato Y, Wazir M, Smith W, Frey E, Yuh WTC, Hanson J, Franken EA. Hippel Lindau disease: MR imaging. Radiology 1988;166:241-6.

5 Seizinger BR, Rouleau GA, Ozelius LJ, Lane AH, Farmer GE, Lamiell JM, et al. Von Hippel-Lindau disease maps to the region of chromosome 3 associated with renal cell carcinoma. Nature 1988;332:268-9.

6 Latif F, Tory K, Gnarra J, Yao M, Duh F-M, Orcutt ML, et al. Identification of the von Hippel-Lindau disease tumor suppressor gene. Science 1993;260:1317-20.

7 Crossey PA, Richards FM, Foster K, Green JS, Prowse A Latif $\mathrm{F}$, et al. Identification of intragenic mutations in the von Hippel-Lindau disease tumor suppressor gene and correlation with disease phenotype. Hum Mol Genet 1994; 3:1303-8

8 Chen F, Kishida T, Yao M, Hustad T, Glavac D, Dean D, et al. Germline mutations in the von Hippel Lindau disease tumor suppressor gene: correlations with phenotype. tumor suppressor gene: correl

9 Jones MH. Yamakawa K. Nakamura Y. Isolation and characterization of 19 dinucleotide repeat polymorphisms on chromosome 3p. Hum Mol Genet 1992;1:131-3.
10 Richards FM, Maher ER, Latif F, Phipps ME, Tory K, Lush $\mathrm{M}$, et al. Detailed genetic mapping of the von HippelLindau disease tumour suppressor gene. 7 Med Genet 1993;30:104-7.

11 Filling-Katz MR, Choyke PL, Oldfield E, Charnas L, Patronas NJ, Glenn GM, et al. Central nervous system involvement in von Hippel Lindau disease. Neurology 1991; 41:41-6.

12 Otten P, Pizzolato GP, Rilliet B, Berney J. 131 Cases of cavernous angioma (cavernomas) of the CNS discovered by retrospective analysis of 24535 autopsies. Neurochirurgie 1989;35:82-3.

13 Dubovsky J, Zabramski JM, Kurth J, Spetzler RF, Rich SS, Orr HT, Weber JL. A gene responsible for cavernous malformations of the brain maps to chromosome 7q. Hum Mol Genet 1995;4:453-8.

14 Horton WA, Wong V, Eldridge R. Von Hippel-Lindau disease: clinical and pathological manifestations in nine families with 50 affected members. Arch Intern Med 1976; 136:769-77.

15 Maher ER, Webster AR, Richards FM, Green JS, Crossey PA, Payne SJ, Moore AT. Phenotypic expression in von Hippel-Lindau disease: correlations with germline VHL gene mutations. $\mathcal{F}$ Med Genet 1996;33:328-32. 